\title{
Uso dos Softwares Geogebra e Winplot no Estudo de
}

\author{
Funções Transcendentes
}

\section{Use of the Softwares Geogebra and Winplot in the Transcendental Functions Study}

\author{
Acárem Chrísler Ferreira dos Santos \\ acarem01@.gmail.com
}

\author{
Josué Antunes de Macêdo \\ josueama@gmail.com
}

\begin{abstract}
Resumo
O presente trabalho apresenta resultados de uma pesquisa realizada com acadêmicos dos cursos de Licenciatura em Matemática e Física, do Instituto Federal de Educação, Ciência e Tecnologia do Norte de Minas Gerais (IFNMG), Câmpus Januária. A metodologia utilizada contempla os parâmetros da sequência didática, embasada nas ideias de Zabala (1998). Para a realização da pesquisa, foi oferecido um curso de extensão, para o qual foram propostas sequências didáticas com ênfase no tratamento gráfico, com o uso das mídias lápis e papel e dos softwares Winplot e Geogebra. O objetivo foi identificar o como as Tecnologias de Informação e Comunicação, podem contribuir para a melhoria da Educação Matemática; e contribuir para a ampliação dos conhecimentos dos cursistas na área da Informática integrada à Matemática. Realizou-se uma abordagem qualiquantitativa para o levantamento e análise de dados, através de questionários e observações feitas no curso. Assim, verificou-se as reflexões, dúvidas e defasagens de aprendizagem apresentadas pelos acadêmicos, possibilitando observar a relevância da utilização da Informática na formação de professores atualmente, e como a integração das TICs ao ensino e aprendizagem de Matemática, podem contribuir para melhorias educacionais significativas, sendo de grande relevância na formação e atuação de professores nos dias atuais.
\end{abstract}

Palavras-chave: Formação de professores. Winplot e Geogebra. Tecnologias de Informação e Comunicação.

\begin{abstract}
This paper presents results of a survey conducted with academic of the licenciates courses in Mathematics and Physics, of the Federal Institute of Education, Science and Technology North of Minas Gerais (IFNMG), Campus Januária. The methodology used includes the parameters of the didactic sequence, based on the ideas of Zabala (1998). For the research, an extension course was offered, for which they were proposed teaching sequences with emphasis on graphic treatment, with the use of pencil and paper media and Winplot and Geogebra software. The objective was to identify how information and communication technologies can contribute to the improvement of mathematics education; and contribute to the expansion of knowledge of the course participants in the field of Integrated Informatics to mathematics. We conducted a qualitative-quantitative approach to data gathering and analysis, through questionnaires and observations made in the course. Thus, it was found the reflections, questions and learning lags presented by academics, enabling to observe the relevance of the use of IT in training teachers today, and as the integration of ICT in teaching and learning mathematics can contribute to significant educational improvements It is of great importance in the formation and performance of teachers today.
\end{abstract}

Keywords: Teacher education. Winplot and Geogebra. Information and Communication Technologies. 


\section{I - Introdução}

Atualmente, presencia-se o constante crescimento e desenvolvimento das tecnologias digitais, e pode-se dessa forma perceber estar-se diante de um momento histórico, no qual grande parte da sociedade possui acesso e utiliza algum tipo de equipamento tecnológico no seu cotidiano. A crescente disseminação da utilização de materiais digitais, como os celulares, os televisores digitais, calculadoras, entre outros, auxiliam diversas áreas do conhecimento, e em relação aos computadores, essa realidade não é diferente. Entretanto, nota-se que muitos usuários desses materiais, principalmente dos computadores desconhecem ou pouco refletem acerca das ferramentas oferecidas nos programas e aplicativos (softwares) existentes nesses equipamentos e muito menos imaginam que seja possível que estes auxiliem no processo de ensino e aprendizagem de algum conteúdo ou disciplina.

Dessa maneira, "No momento em que os computadores, enquanto artefato cultural e enquanto técnica fica cada vez mais presente em todos os domínios da atividade humana, é fundamental que eles estejam presentes nas atividades escolares" (BORBA; PENTEADO, 2007, p. 87). Assim, a sociedade, o sistema de ensino e as escolas necessitam se adequar ao crescente desenvolvimento da tecnologia e da informática e utilizar as Tecnologias de Informação e Comunicação (TICs) na área educacional.

Neste sentido, as instituições de ensino, precisam se adequar a essa realidade, promovendo ações concretas, haja vista que é notável o fato de que o uso da informática nas aulas tem a possibilidade de gerar mudanças de grandes amplitudes, que além de propiciar novas dinâmicas em sala de aula, pode resultar em outras consequências diretas ou indiretas à educação. No entanto implantar essas mudanças nas instituições de ensino é um grande desafio, pois existem inúmeros fatores desencadeadores, tais como adequação do currículo, melhoria na gestão escolar, disponibilização de ambientes informatizados satisfatórios e de qualidade; além da formação contínua dos profissionais da educação na área de informática.

Essa realidade requer do professor um posicionamento diferenciado, uma reflexão e transformação de sua prática, além de constantes estudos para utilizar as tecnologias digitais a seu favor. Do contrário, ficará estagnado numa prática docente sem avanços, rotineira, que caiu na mesmice, na qual, na maioria das vezes há insatisfação e falta de motivação, não apenas por parte destes, mas também por parte dos alunos que anseiam por mudanças, além de novas propostas e metodologias de ensino. Os professores são em grande parte, responsáveis pela organização do ambiente de aprendizagem no qual atuam, assim como pela qualidade do mesmo, através de suas atitudes e posicionamentos referentes às possibilidades 
que lhes são apresentadas no cenário educacional. E no que diz respeito à informática na educação, essa responsabilidade não se isenta, haja vista que:

Por sua vez, na ação do professor na sala de aula e no uso que ele faz dos suportes tecnológicos que se encontram à sua disposição, são novamente definidas as relações entre o conhecimento a ser ensinado, o poder do professor e a forma de exploração das tecnologias disponíveis para garantir melhor aprendizagem pelos alunos. (KENSKI, 2009, p. 19).

Corroborando com as ideias de Pais (2008), pois de acordo com este autor a utilização qualificada da informática como suporte didático, tem como consequência implicações na prática, culminando na transformação da maneira como o trabalho docente se organiza.

Os recursos digitais que propiciam a melhoria $\mathrm{e}$ ampliação das formas de ensino/aprendizagem, como por exemplo, alguns softwares tais como o geogebra, o Winplot, o Archimedes, o Geo3D, o Dr. Geo, entre outros; e a internet possibilitam que haja interatividade entre o usuário e o computador, situação que pode acarretar numa aprendizagem mais significativa do mesmo. Neste contexto, "os professores e alunos podem utilizar as tecnologias da informação para estimular o acesso à informação e à pesquisa individual e coletiva, favorecendo processos para aumentar a interação entre eles". (MORAN; MASETTO; BEHRENS, 2006, p. 97)

Em relação à aprendizagem significativa, é importante salientar que:

A aprendizagem é muito mais significativa à medida que o novo conteúdo é incorporado às estruturas de conhecimento de um aluno e adquire significado para ele a partir da relação com seu conhecimento prévio. (PELIZZARI et al., 2002, p. 38)

Dessa forma, é necessário que o educador valorize os conhecimentos prévios que procedem dos alunos, e seja mediador entre estes conhecimentos e os conhecimentos sistematizados, para que os alunos vejam significado naquilo que estão aprendendo e sintam-se mais motivados.

As tecnologias digitais utilizadas na educação podem tornar possível a interação entre aluno e ferramentas tecnológicas, através do ensino e da aprendizagem de como manuseá-las adequadamente, de maneira que será possível aplicar os conhecimentos assimilados no dia-adia. Sendo assim, a utilização de softwares dinâmicos com suas interfaces que se tornam cada vez mais bem elaboradas, geram possibilidades diversificadas, que proporcionam interatividade entre o aluno, o computador e o conteúdo abordado. Dessa maneira, estes possuem um grande potencial para serem utilizados nas escolas. Tem-se ainda que, o uso da internet é, "um importante meio para a obtenção de informações, sendo estas entendidas como matéria prima para a elaboração do conhecimento" (PAIS, 2008, p. 20). 
Assim, verifica-se que é imprescindível a presença da internet também como recurso útil no ambiente educacional para que não apenas os alunos, mas todos aqueles envolvidos no processo de ensino e aprendizagem aprendam e se conscientizem que esta é de grande importância, haja vista que sua aplicabilidade se estende ao cotidiano da maioria de nós, devido à possibilidade de acesso a inúmeras fontes de informação existente.

Nesse sentido, os alunos devem saber utilizá-la como auxilio na ampliação de conhecimentos, através de pesquisas, leituras, e não apenas para diversão e/ou entretenimento encontrados em jogos, redes sociais, entre outros. Neste contexto, o aluno, ao possuir acesso à internet e a qualquer outra ferramenta que envolve a tecnologia digital, tem a possibilidade de desenvolver-se e tornar-se um cidadão com inúmeras capacidades e competências necessárias para sobreviver na sociedade atual.

\section{II - Metodologia, resultados e discussões}

\section{1 - Metodologia}

Esta proposta consiste no desenvolvimento dos tópicos das funções Transcendentes ou Transcendentais. De acordo com Stwart essas funções:

São as funções não algébricas. O conjunto das funções transcendentais inclui as funções trigonométricas, trigonométricas inversas, exponencial e logarítmica, mas também inclui um vasto número de outras funções que nunca tiveram nome. (STWART, 2013, p. 35)

Dessa maneira, neste trabalho, foram abordados os conteúdos: funções trigonométricas, trigonométricas inversas, exponencial e logarítmica. Aconteceu assim o desenvolvimento de sequências didáticas fundamentadas em Zabala (1998), visando utilizar os elementos destas para manter unidade na prática educativa com três fases de uma intervenção reflexiva: planejamento, aplicação e avaliação. As sequências didáticas são conjuntos de atividades ordenadas, estruturadas e articuladas para a realização de certos objetivos educacionais, que têm um princípio e um fim conhecidos tanto pelos professores como pelos alunos (ZABALA, 1998).

Buscou-se valorizar os conhecimentos prévios dos cursistas em relação aos conteúdos propostos e demonstrar significados e relevância em estudar os mesmos, com ênfase maior na apresentação das ferramentas dos softwares Winplot e Geogebra, pois através do desenvolvimento de atividades práticas, foi possível observar suas aplicabilidades e utilidades no ensino e na aprendizagem de Matemática, assim como no cotidiano dos próprios acadêmicos.

A presente pesquisa é ao mesmo tempo qualitativa e quantitativa. É quantitativa na medida em que são tabulados e quantificados alguns dos dados que foram analisados, sendo possível efetuar cálculos, no intuito de mostrar de maneira objetiva e clara se os objetivos previamente traçados foram alcançados ou não, pois de acordo com Bicudo, "O quantitativo tem a ver com 
o objetivo passível de ser mensurável. [...]. Embutida no seu significado está também a ideia de racionalidade entendida como quantificação" (2006, p. 105). Já a parte qualitativa se faz presente na medida em que se pretende mostrar e descrever sobre relatos de experiências, observações de comportamentos, relatos de respostas de questões abertas, dentre outros procedimentos que não são possíveis de se quantificar.

\section{Campo, sujeitos e objetivos da pesquisa}

Para a realização desta pesquisa, foi oferecido um curso de extensão intitulado Funções transcendentes com o uso dos softwares Winplot e Geogebra para acadêmicos dos cursos de licenciaturas em Matemática e Física, do Instituto Federal de Educação, Ciência e Tecnologia do Norte de Minas Gerais (IFNMG). No curso, abordou-se o conteúdo de funções transcendentes, ao enfatizar a parte gráfica, visando identificar a aplicabilidade destes softwares durante a formação inicial de professores de Matemática e Física, assim como sua possível utilização no cotidiano dos acadêmicos de forma sistematizada.

O curso foi ministrado em dez semanas, com uma carga horária total de quarenta horas, na modalidade semipresencial, utilizando o Ambiente Virtual de Aprendizagem Moodle, como uma ferramenta de aprendizagem colaborativa.

Nos encontros presenciais, conforme o mostrado na figura 1, num total de dez ao todo, com duas horas de duração cada, foram trabalhados os conteúdos de funções transcendentes, utilizando os softwares Winplot e Geogebra. A amostra foi constituída de vinte e um alunos dos diversos períodos das licenciaturas do IFNMG, sendo dezessete de Matemática, e quatro de Física.

Figura 1: Alunos do Curso em aula no laboratório de informática.

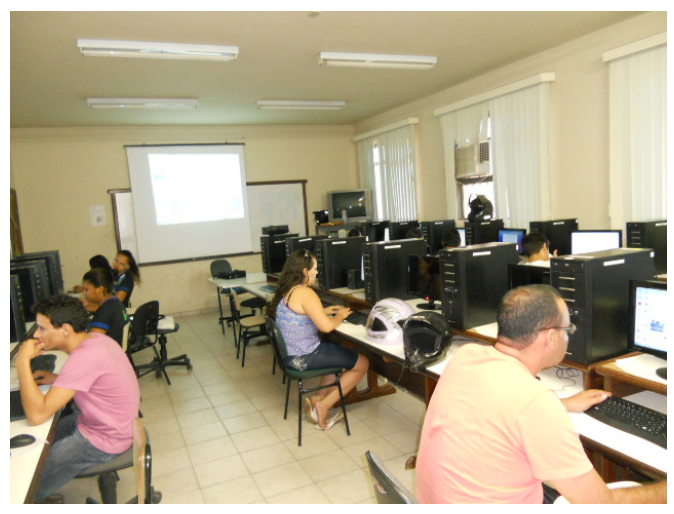

Fonte: Dados da pesquisa.

O conteúdo escolhido, funções transcendentes, mesmo que possibilite que as noções teóricas sejam absorvidas rapidamente pelos alunos, nem sempre são bem compreendidas por eles, pois na maioria das vezes, raramente estuda-se no Ensino Médio e nos períodos iniciais da graduação. Objetivou-se, que acadêmicos participantes do curso familiarizassem com as 
definições das funções apresentadas ao revisar aquelas já estudadas e analisar as desconhecidas, conseguindo dessa forma construir a sua representação gráfica utilizando um dos softwares (ou ambos), assim como a possibilidade ou não de se realizar a representação gráfica através das mídias lápis e papel.

Diante dessa realidade, foram sugeridas atividades para serem desenvolvidas no computador, e muitas foram realizadas com o auxilio do Geogebra ou do Winplot, tanto nas aulas presenciais como nas aulas virtuais. Neste contexto, foram realizadas atividades de apoio à aprendizagem dessas funções, assim como a resoluções de problemas, para tornar os conteúdos mais atraentes e facilmente compreendidos para os cursistas. Isso porque é preciso:

\footnotetext{
Integrar tecnologia, metodologias, atividades. Integrar texto escrito, comunicação oral, escrita, hipertextual, multimídica. Aproximar as mídias, as atividades, possibilitando que transitem facilmente de um meio para o outro, de um formato para o outro. Experimentar as mesmas atividades em diversas mídias [...] (MORAN; MASETTO; BEHRENS, 2006, p. 31)
}

Assim, foi realizado o uso de uma série articulada e ordenada de atividades, no intuito de formar unidades didáticas (Zabala, 1998). Zabala trata de referenciais para a análise de quatro sequências didáticas que correspondem a quatro exemplos (ou modelos) de unidades didáticas (ou de intervenção). Ao analisar as unidades existentes, valorizando a aprendizagem significativa dos acadêmicos que participaram do projeto, e na sequência de conteúdo que propiciaria esta realidade, apresentaram-se, as definições, principais conceitos, propriedades e atividades referentes às seguintes funções transcendentes: Exponenciais; Logarítmicas; Trigonométricas Diretas e Inversas.

\section{3 - Critérios de escolha dos softwares Winplot e Geogebra}

Os softwares Winplot e Geogebra foram escolhidos por serem dinâmicos, gratuitos e acessíveis a todos que se interessar em aprender a manusear suas ferramentas. Além disso, objetivou-se com isso apresentar estes softwares aos cursistas, haja vista que a maioria os desconhecia, e consequentemente não sabiam manusear suas ferramentas.

O Geogebra é, segundo Guimarais (2010) um software de Matemática Dinâmica, gratuito e de código aberto. Pode ser instalado em qualquer computador, que contenha o programa Java. Reúnem recursos da Álgebra, Cálculo e Geometria. Ele foi criado por Markus Hohenwarter e uma equipe internacional de programadores em 2001, na University of Salzburg, localizado na cidade de Salzburg, Estado de Salzburgerland, na Áustria (Hohenwarter; Hohenwarter).

De acordo com Mota (2010), o software Winplot é um programa simples de ser utilizado, ele dispensa o conhecimento de qualquer linguagem de programação e também é um software de distribuição gratuita. Foi desenvolvido pelo Professor Richard Parris da Philips Exeter 
Academy, nos Estados Unidos, por volta de 1985 e traduzido para o português em 2001 pelo professor Adelmo Ribeiro de Jesus, na Universidade Federal da Bahia. Este programa permite o traçado de gráficos em duas ou três dimensões, a partir de equações matemáticas.

\section{4 - Coleta, análise e Reflexão dos dados da Pesquisa}

No período de desenvolvimento do curso de extensão sobre Funções transcendentes com o uso dos Softwares Winplot e Geogebra, foram coletados alguns dados relevantes à presente pesquisa, para serem analisados de maneira qualitativa e quantitativa. Os dados foram obtidos através de dois questionários preenchidos pelos cursistas, um no primeiro dia e outro no último dia do curso, além disso, houve observação e análise da forma como os cursistas realizaram as atividades, as representações gráficas, quais as reflexões e dúvidas expressas, e ainda o envolvimento e compromisso deles com as atividades propostas.

Foi interessante observar a insatisfação por parte de alguns cursistas em ter que preencher os questionários, principalmente nas questões em que se fazia necessário comentar as respostas. Essa atitude é claramente notada em muitos acadêmicos que fazem curso de Ciências Exatas, muitos demonstram dificuldades em expressar sua opinião ou ponto de vista através da escrita.

Neste contexto, analisou-se o conhecimento prévio dos acadêmicos participantes no que diz respeito ao nível de conhecimento em informática, notou-se que a maioria possui um nível básico em informática, como pode ser analisado no gráfico 1, sabe utilizar alguns programas, acessar internet, manusear algumas ferramentas; enquanto a minoria possui conhecimento intermediário ou avançado em se tratando de informática.

Gráfico 1: Nível de conhecimento em informática dos acadêmicos.

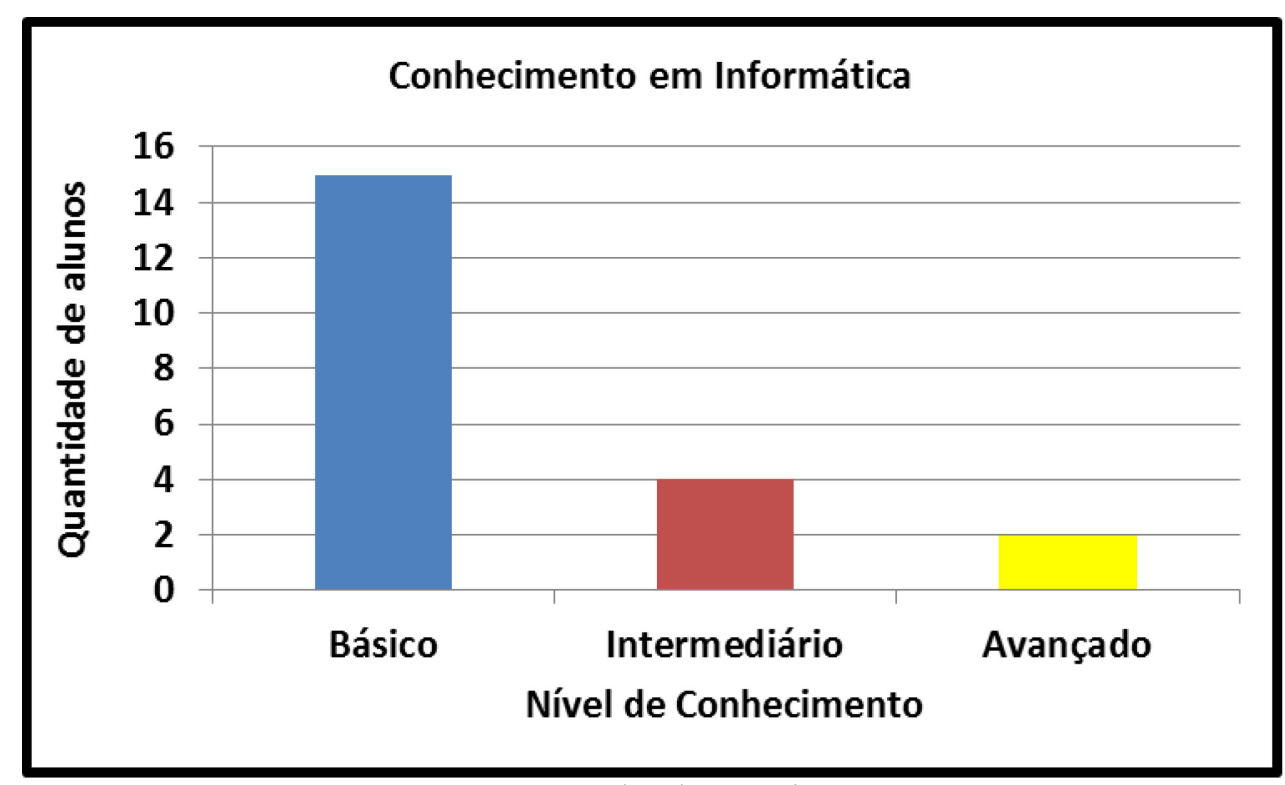

Fonte: Dados da pesquisa. 
Em relação ao conhecimento prévio sobre os softwares Winplot e Geogebra, a maioria não possuía, enquanto a minoria conhecia os dois softwares superficialmente, mas pretendiam ampliar seus conhecimentos com relação aos mesmos.

Quando questionados sobre o que pensam em relação ao uso das TICs no Ensino da Matemática, foram unânimes em ressaltar sua relevância não apenas no Ensino da Matemática, mas em todas as demais áreas de ensino, e relataram ainda o fato de que os profissionais da educação devem estar preparados para integrarem as TICs em suas práticas docentes, no intuito de proporcionar aulas mais atrativas e dinâmicas, objetivando melhorias na relação professor/aluno, assim como mudanças positivas no processo de ensino e aprendizagem.

A satisfação dos alunos em relação ao curso de extensão foi satisfatória, como salienta o acadêmico 2:

Acadêmico 2: Os dois softwares são de grande importância para o auxílio de funções que são difíceis de interpretar, e através do conhecimento que pude adquirir sobre eles, me identifiquei mais com o Winplot, pois é mais fácil de manusear. O curso foi uma grande oportunidade para que houvesse a expansão do conhecimento que eu possuía sobre esses softwares, pena que o tempo foi curto. Para um bom professor, o uso da tecnologia é um auxílio importantíssimo se usado de forma correta.

Já a opinião do acadêmico 3 é que:

Acadêmico 3: $O$ uso dos softwares é uma maneira de fazer os alunos se interessarem pela matemática, pois com eles os conceitos podem ser melhor compreendidos, além de tornar o ensino mais prazeroso uma vez que facilita a comunicação entre professor e aluno. O curso vai ter grande relevância na minha formação. Pena que acabou. Acho que a carga horária poderia ter sido mais intensa, assim, poderíamos aprofundar mais nos conteúdos abordados.

Foram mostradas algumas ferramentas dos softwares Geogebra e Winplot aos acadêmicos, principalmente aquelas que apresentam maior relevância e que mais foram utilizadas durante o curso, de maneira que os acadêmicos participantes realizaram as atividades propostas no próprio software, no intuito de se familiarizarem com os recursos disponíveis, para assimilarem os conhecimentos propostos durante o curso, dessa forma, os acadêmicos puderam analisar as diferenças entre as ferramentas dos dois softwares. Apesar de alguns acadêmicos demonstrarem mais dificuldades do que outros ao manusear algumas ferramentas dos softwares para realizar as atividades propostas, as aulas transcorreram tranquilamente, e na medida do possível, tiravam-se as dúvidas, auxiliando-os, quando solicitado.

Aconteceu a apresentação das funções transcendentes, seguida de discussão sobre as especificidades e comportamento das mesmas, além da realização das atividades propostas de 
maneira que todos participassem e expressassem seu ponto de vista, desse modo muitos manifestaram sua perplexidade ao analisar o quanto a utilização dos softwares pode auxiliar no ensino e aprendizagem da Matemática.

As resoluções e atividades referentes aos conteúdos propostos, realizadas em sala de aula ou em casa, foram postadas no Moodle, que é um ambiente virtual de aprendizagem (AVA). Em algumas atividades foi requisitado aos alunos a plotagem dos gráficos das funções propostas, não apenas em um dos softwares, mas também nas mídias lápis e papel. Ao propor o desenvolvimento da atividade com lápis e papel, alguns acadêmicos demonstraram certa resistência, alguns expressaram possuir dificuldades para esboçar os gráficos, enquanto outros demonstraram estar familiarizados com as atividades.

Essa realidade pode ser observada nas resoluções de algumas atividades propostas, como nas figuras 2 e 3 .

Figura 2: Resolução de exercícios sobre função exponencial do aluno B com as mídias lápis e papel.

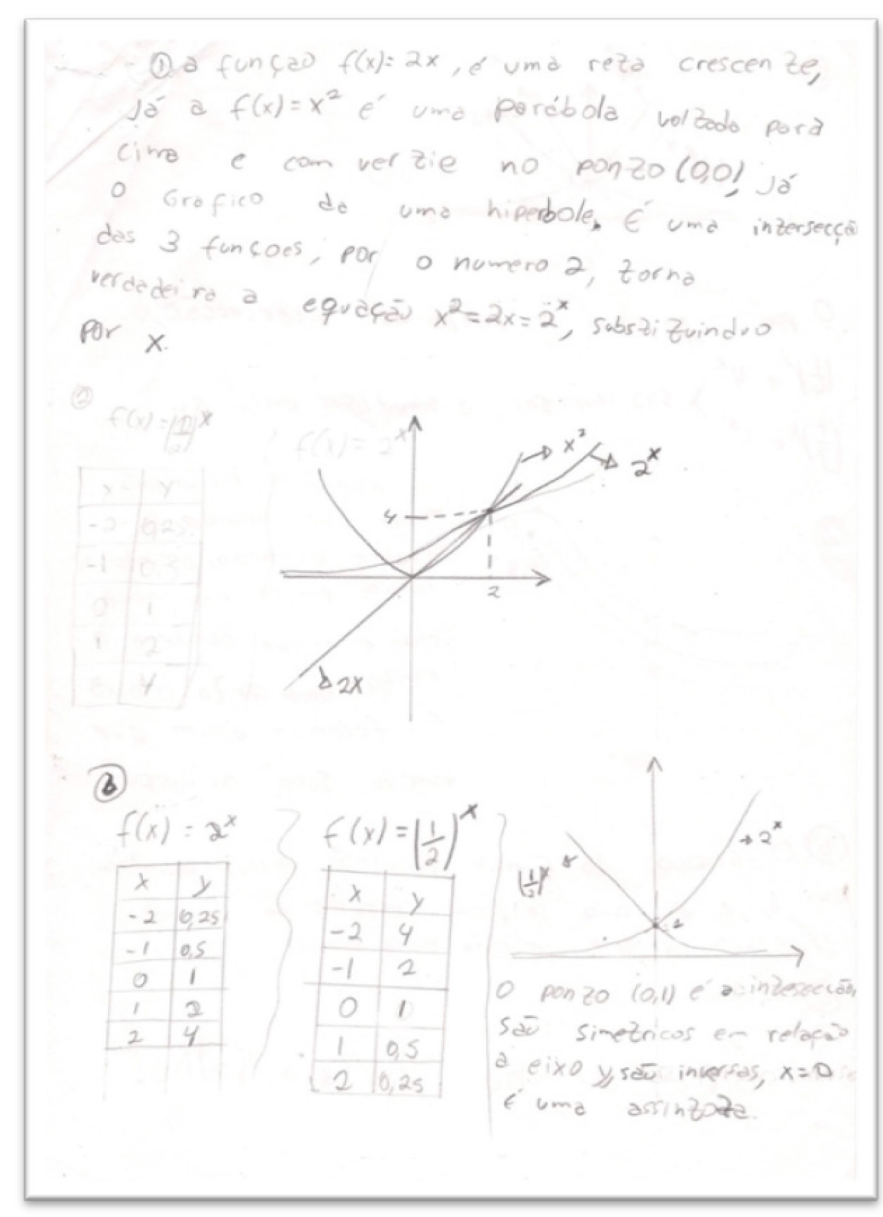

Fonte: Dados da pesquisa. 
Depois de feita a resolução utilizando a mídia lápis e papel, solicitou-se ao aluno que realizasse a mesma atividade, agora utilizando o software Winplot, sendo o resultado mostrado na figura 3 , abaixo.

Figura 3: Resolução de atividade sobre função exponencial do aluno B, plotado no software Winplot.

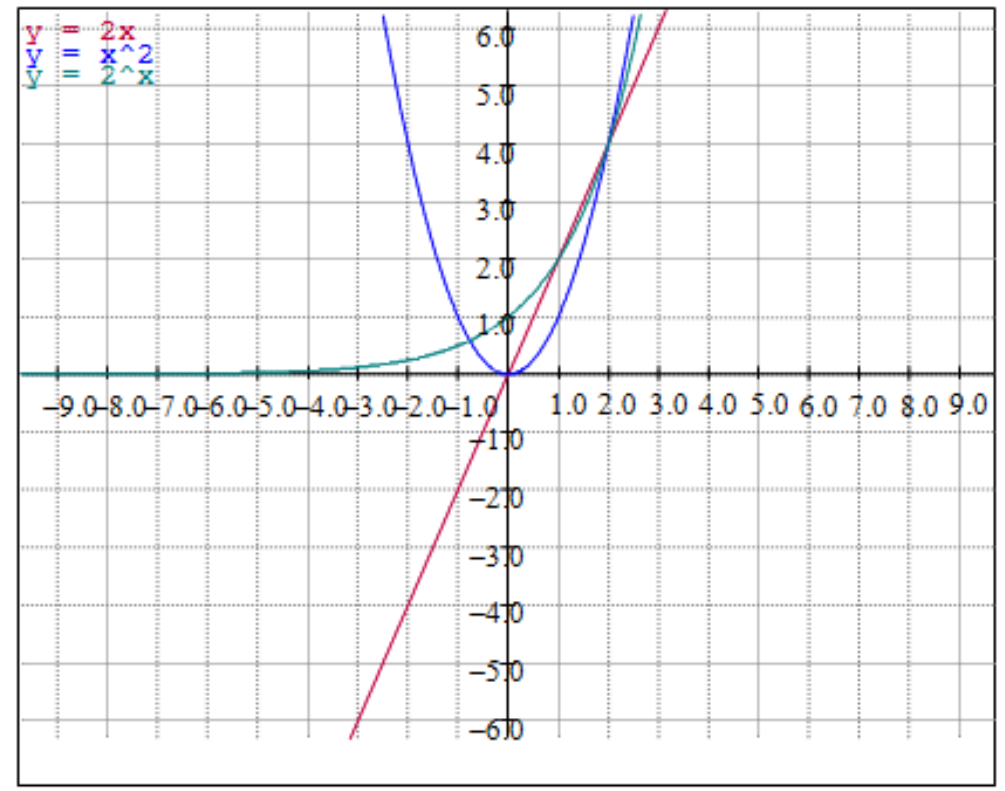

Fonte: Dados da pesquisa.

Notou-se, dessa forma, que ao integrar o uso dos softwares ao tratamento das funções previstas, no momento da realização de determinadas atividades, alguns acadêmicos apresentaram facilidade e outros nem tanto, principalmente no que diz respeito ao domínio e análise de alguns conceitos e notações matemáticos na representação gráfica das funções, e ao escrever as linguagens matemáticas adequadas e plotar os gráficos no papel.

\section{III - Considerações finais e conclusões}

A realização da pesquisa foi gratificante, pois contribuiu, com sua relevância, para a formação não apenas acadêmica, mas pessoal e profissional de todos os envolvidos direta ou indiretamente com a mesma. Isso se deu pelo fato de quão foi notória a participação dos acadêmicos que demonstraram interesse em aprender manusear as ferramentas dos softwares, ao realizarem as atividades propostas. É importante ressaltar o quanto os cursistas sentiram-se a vontade ao lidar com as ferramentas dos softwares, e desenvolveram-se consideravelmente bem, pois os mesmos encontravam-se solícitos, e demonstraram certa familiaridade com a informática. 
Apesar de alguns alunos terem demonstrado no inicio do curso, possuir certa dificuldade ao lidar com a linguagem matemática, no momento de inserir os diferentes tipos de funções nos softwares, se esforçaram para converter essa situação a seu favor. É inegável a existência da defasagem de aprendizagem de alguns cursistas em relação aos tipos de funções apresentadas, no entanto, a maioria se esforçou e agregou novos conhecimentos que lhes serão muito úteis.

Ao aprender a manusear as principais ferramentas de plotagem de gráficos nos dois softwares utilizados, ficou claro aos cursistas o fato de que é mais fácil e viável utilizar os softwares ao invés das mídias lápis e papel. Essa realidade foi analisada através da resolução de atividades com o auxílio do Software Geogebra, na qual os acadêmicos encontraram dificuldades em resolvê-la apenas com lápis e papel, devido ao seu aparente grau de dificuldade. Assim, a utilização do software facilitou a percepção dos acadêmicos, a visualização de como se comportam aquelas funções, e os mesmos associaram as dificuldades que apresentaram com as dificuldades que muitos alunos demonstram quando estudam o conteúdo de funções no ensino médio, e o quanto seria interessante eles terem acesso à algum tipo de tecnologia, tais como software matemático para auxiliá-los.

No entanto, prevaleceu a consciência dos mesmos acerca das condições na qual se encontra a educação básica atualmente, principalmente a pública, que na maioria das vezes não disponibiliza de subsídios necessários ou recursos tecnológicos adequados e suficientes, para que os professores utilizem qualquer ferramenta tecnológica, seja softwares ou até mesmo internet em suas aulas, tendo estes que utilizar dos meios tradicionais para ensinar os conteúdos, e os alunos, por sua vez continuam a fazer uso das mídias lápis e papel, para aprendê-los.

A utilização dos softwares matemáticos associada à mudança de ambiente de aprendizagem, da sala de aula para ambientes virtuais ou informatizados, foi de relevância incomensurável para que houvesse no decorrer das aulas um melhor desenvolvimento na assimilação dos conhecimentos propostos. Desse modo percebeu-se que a formação inicial ou continuada do profissional da educação, para atuar na sociedade atual, com ampla utilização das tecnologias digitais, necessita possibilitar aos professores o entendimento e a aprendizagem destas tecnologias, assim como novas maneiras de representar, analisar e disseminar o conhecimento, culminando numa transformação visível dos conceitos já conhecidos e possibilitando a busca e compreensão de novas ideias e valores, ligados ao ensino, na maneira de ensinar e aprender, apesar de que, não se pode pensar que a utilização das tecnologias informáticas é solução única e definitiva para os problemas educacionais existentes. Ainda 
assim, não se pode negar ou pensar ser redundante a integração dessas tecnologias ao ensino e aprendizagem não apenas com a Matemática, mas com todas as demais áreas de conhecimento, pois, esta pode contribuir para melhorias educacionais significativas.

\section{Referências}

BICUDO, M. A. V. Pesquisa Qualitativa e Pesquisa Qualitatva segundo a abordagem fenomenológica. In: BORBA, M.C.; ARAÚJO, J. L.(orgs.). Pesquisa Qualitativa em Educação Matemática. Belo Horizonte: Autêntica, 2006. p. 101-113.

BORBA, M. C.; PENTEADO, M. G. Informática e Educação Matemática. Belo Horizonte: Autêntica, 2007. 104 p.

GUIMARAIS, Y. P. B. Q. Exploração de convergência em tópicos de cálculo diferencial, integral e numérico, usando os softwares VCN e Geogebra. 2010. 192 f. Dissertação (Mestrado em Ensino de Ciências e Matemática) - Pontifícia Universidade Católica de Minas Gerais, Belo Horizonte.

KENSKI, V. M. Educação e tecnologias: o novo ritmo da informação. Campinas, SP: Papirus, 2009. 144 p.

MORAN, J. M.; MASETTO, M T.; BEHRENS, M. A. Novas tecnologias e mediação pedagógica. Campinas, SP: Papirus, 2006. p. 133-173.

MOTA, J. F. Um estudo de planos, cilindros e quádricas, explorando seções transversais, na perspectiva da habilidade de visualização, com o software winplot. 2010. 205 f. Dissertação (Mestrado em Ensino de Ciências e Matemática) - Pontifícia Universidade Católica de Minas Gerais, Belo Horizonte.

PAIS, L. C. Educação escolar e as tecnologias da informática. Belo Horizonte: Autêntica, 2008. $168 \mathrm{p}$.

PELIZZARI, A. et al. Teoria da aprendizagem significativa segundo Ausubel. Rev. PEC, Curitiba, v.2, n.1, p.37-42, 2002.

STWART, J. Cálculo. São Paulo: Cengage Learning, 2013. 688 p.

ZABALA, A. A prática educativa: como ensinar. Porto Alegre: Artmed, 1998. 224 p. 